\title{
Role of Public Libraries on Women Empowerment: A Study with Special Reference to District Library Malappuram
}

\author{
Sasi P.K \\ Research Scholar Department of Library and Information Science University of Calicut.
}

\begin{abstract}
The present study focused on the role public library on women empowerment. Population of the present study is woman users of District library Malappuram. Questionnaire was used for collecting data. 250 questionnaires were distributed and over 175 questionnaires were returned. Various information sources of the library are not sufficient to meet the needs of women users and the infrastructure and facilities of the library has to be improved. Majority of the women under study are not aware of the information technology applications. From the analysis, it concluded that library has to play a vital role for the improvement of women.
\end{abstract}

Keyword: Public Library, Women Empowerment. Malaapuram District

\section{Introduction}

Empowering women has become the focus of considerable discussion and attention all over the world as well as associated with research in many educational disciplines including that of adult education. Today women is stigmatised and rebuked by the family and the society. In an attempt to bridge gender disparity in the developing world different agencies are trying to elevate the status of women so that they become increasingly visible in various roles such as socio economic, political and civil leadership. Over two decades of the women's movement across India, we have seen an increasing emphasis on the promotion of grass roots level organisation for women development and discussions as women status and empowerment.

In India women are more than man, most of this Women are living in bad condition they are suffering various problems since independence; the Government has implemented several empowerment programmes to develop or empower the Women. But they have not made any remarkable improvement in their living conditions. It can be mainly attributed to the non availability of education and information on the emerging technologies. Therefore, transfer of new technologies to the rural communities has become essential to empower them with education, power and position; it challenges social conventions and customs. Women education influences all the family members with whom she deal and it helps to eradicate the poverty and thereby triggering development. ( S K Ravikumar 2006) ${ }^{1}$. Libraries occupy an important place in modern society as an agent of educational, informational, political economic and antiquarian functions. Libraries are the only agency devoted solely to the purpose of collecting preserving, transmitting and securing the widest and most effective use of the records of civilisation by the society of which it is a part. This study aim to evaluate the different activities of the public library in women empowerment.

Public library is a local centre for information making all kind of knowledge and information readily available to its users. Its service is open to all, and has a key role in collecting, organizing and exploiting information, as well as providing access to a wide range of information sources. The nature of library use is changing rapidly. New frontiers of technology and the ever-changing information landscape have created endless possibilities for those who seek information. In modern society people need great demand for information in different areas of life. Educated society are bothered about the technological development of information systems, such as computers, telecommunications. The libraries are thriving to meet the demands of users.

\section{Library}

Library is not just a building stacked with books and manuals. It is a repository and source of information ideas, a place for learning enquiry generation of thought and creation of new knowledge (Bhuvaneshwari ravi, and Gayatri Vivek, 2013) ${ }^{2}$. Libraries have always played a vital role in promoting education and research, developing reading habits and dissemination of knowledge and information.

Libraries are one of the most important components of the information age and librarians are dealing successful with new technological advances. Librarians work on helping society; understand the value and contributions of libraries particularly in the areas of organizing, preserving and providing access to information. 


\section{Public Library}

Public library as its name suggests, it is for the people, by the people and of the people. It exists from civilization of mankind and act as the important custodian of human culture, knowledge and social customs.(Kaliya Perumal and Bahskarn, 2010). ${ }^{3}$. It is necessary to maintain well trained and highly motivated staff to make effective use of the resources of the library and to meet the demands of the community. UNESCO define public Library as the local gateway to knowledge provides a basic condition for lifelong learning, independent decision making and cultural development and social group. (UNESCO manifesto 2005). The UNESCO manifesto also state that it should be an institution established under the clear mandate of law maintained fully from public fund, offering all its service free of cost and open for free and equal use by all members of the community irrespective their age, sex, religion, language structural level of education. The origin of the public library service vests in antiquity with the first recording of the human thought took birth the concept of a system or an institution which could preserve thought for future use which gradually came to be referred by the term library. Ever since the essential functions of all libraries remained the same collection, preservation and dissemination of knowledge. Public library is a welfare centre which provides useful service to the community by fostering education, ,promoting culture, providing scope for healthy recreation and disseminates information to all section of the society.(Laila T Abraham 2010) ${ }^{4}$

\subsection{Objectives of Public Library}

The basic objective of a public library is to circulate books, most of the enunciation of the objectives of public library assign to its important roles in educational, economic, political, social and cultural development of the country. The explosive growth of knowledge and the direct relation of information to development in all walks of human life have elevated public library which is to give people free access to information, as the most important instrument in their life and progress. There is no other substitute to public library which is of such importance and which can undertake the vast and varied functions, it expected to undertake in the present day society the characteristics of which is tremendous and continuous development.

\subsection{Function of Public Library}

Library which are fulfilling the reading requirements of the citizen to the fullest extent without making any discrimination on the basis of membership as other academic libraries. Thus it considered as Peoples University and as such library will focus on providing knowledge on all matters including academic and non - academic. But in large number it focus on general knowledge, Novels, Stories, Drama, Autobiography, Magazine, and Daily Newspapers. These resources are used by women in large number. Now a-day public libraries are functioning as mobile -channels in providing knowledge to the people of rural and urban areas.

Public libraries are continuing to serve important community function, but that the future of those institutions is not assured to perform various important roles in educational, economic, political, social and cultural development of the country. Information, as the most important instrument in their life and progress it will lead to explosive growth of knowledge and direct relation of information to developments in all walks of human life have elevated public library which is to give people free access.

\subsection{Centre for Education}

Public library has to offer materials and services to the people to understand social phenomenon and thus live successful social life and social evils. It provides opportunities to the people to understand social evils and methods to control them. ( Kaliya Perumal and Baskaran, 2010) ${ }^{5}$ Education is for complete living of man, so bread and butter aim is an inevitable aspect- hence the importance of vocation .To get the preferred vocation, one should qualify the basic requirements regarding the same. The role of modern Public libraries is to educate ever citizen by providing access to their collection in different formats and various service. It supplements formal education and support the informal education and continuing self education. Public library will promote education at all levels primary, secondary, higher, non-formal, adults, distant. Vocational and so on.

\subsection{Centre for cultures}

Public library, a part from being a centre of education and information, is required to serve as a centre to promote local or regional culture. For this the public libraries has to acquire all recorded material of mankind depicting this excellence in prose, poetry, drama, music, painting, dance and sculpture.

\subsection{Centre for Information}

Public library are the local gateway to knowledge and it should provide basic condition for life long learning, decision making and it provide information suiting needs of individual and groups. To overcome the poverty library needs to disseminate information which can use for the employment, skill development or in generating self employment activity. Information is that basic need of life, which is helps in the proper 
fulfilment of other needs such as food, shelter etc,

\section{District Library Malappuram}

Based on the libraries, the public libraries are categorised into different types viz, State library, District library, Taluk Library, Village Library. The district library Malappuram is a public library established in 1972. This library is located in Kottapadi, a central place in Malappuram area and near the collectorate.

\subsection{Administrative Set up of the District Library Malappuram}

The administrative set up of the library includes president, vice president, secretary, joint secretary and 7 members. The staff in the library comprises of a chief librarian and one assistant. The librarian is well experienced in his profession. Library is working in a rented building with separate rooms for reading and stacking.

The collection of library includes all types of books, periodicals, reference, newspaper in the different language this collection details are given in the following table.

Table 1: Total collections in Malappuram Public Library

\begin{tabular}{|c|c|c|c|}
\hline Language & Books & Periodicals & Newspaper \\
\hline Malayalam & 5500 & 40 & 9 \\
\hline Hindi & 6000 & 4 & - \\
\hline English & 5000 & 14 & 1 \\
\hline Subjects & 550 & 5 & - \\
\hline Total & 17050 & 63 & 10 \\
\hline
\end{tabular}

\section{Objectives Of The Study:}

Following are the objectives of the study;

- To find out the frequency of use of Public libraries by women

- To identify which information services of public libraries is mostly used by women

- To find out use and awareness of Information and Communication Technology tools and services of public library by woman for empowerment.

- To evaluate the role played by the public libraries in educational, cultural and socio-political development for women.

- To suggest suitable measures for women empowerment that can be undertaken by public library

\section{Methodology}

For the present study, questionnaires were used as the major tool for the collection of data for the study. These were designed in two parts, one part with the personal details and the other with logically selected questions about the problem under study. Informal interviews were conducted with librarian in order to understand their view about the topic of study.

The clientele of the Malappuram District library comprises of people from almost all walks of life. The major users are students, housewives, government employees and others. Random sampling technique was used for the study. 250 questionnaires were distributed and over 175 questionnaires were returned. For analysis percentage method was adopted.

\section{Analysis And Interpretation}

Data analysis and interpretation is considered as the heart of research report. Analysis means critical examination of assembled and grouped data for studying the characteristics of objects under study and for determining the pattern of relationship among the variables relating to it. The collected data is analysed and presented in the form of tables and figures with necessary interpretation as below:

\subsection{Category-wise Distribution of Data}

The details of category-wise members were collected and the information is tabulated as below.

Table 2: Category-wise Distribution of Data

\begin{tabular}{|l|l|l|l|}
\hline Category & $\begin{array}{l}\text { Number of questionnaires } \\
\text { distributed }\end{array}$ & Responses received & Per cent \\
\hline Housewives & 65 & 33 & 18.96 \\
\hline Students & 55 & 46 & 26.44 \\
\hline Employees & 103 & 78 & 44.83 \\
\hline Non students & 27 & 17 & 9.77 \\
\hline Total & 250 & 174 & 100 \\
\hline
\end{tabular}

As per the table 2 the responses from the employees are the most and the least responses are from nonstudent members. 


\subsection{Frequency of Library Visit}

The frequency of library visit by the user is usually influenced by the factors such as collection, organization and maintenance of the library resources along with the library resource, facilities and the library service. The frequency of library visit and its utilization by the respondents are presented in Table 3 .

Table 3: Frequency of library visit

\begin{tabular}{|l|l|l|}
\hline Frequency & No. of Responses & Percentage \\
\hline Daily & 12 & 6.9 \\
\hline Weekly & 40 & 22.99 \\
\hline Monthly & 72 & 41.38 \\
\hline Occasionally & 50 & 28.73 \\
\hline Total & 174 & 100 \\
\hline
\end{tabular}

Table 3 shows that a good number of the users visits library once in a month (41.38\%). Only $6.9 \%$ of them visit daily.

\subsection{Performance of staff}

The investigator also evaluated the staff with regard to their efficiency, mentality and dedication. It was seen that how their services help the women users in their empowerment. The responses were tabulated in table 4.

Table 4: Performance of staff

\begin{tabular}{|l|l|l|l|l|l|l|l|}
$\begin{array}{l}\text { Category of } \\
\text { users }\end{array}$ & High & Low & Unassumed & Total & & \\
\hline & No & $\%$ & No & $\%$ & No & $\%$ & \\
\hline Housewives & 26 & 78.79 & 4 & 12.12 & 3 & 9.09 & 33 \\
\hline Students & 28 & 60.87 & 10 & 21.74 & 8 & 17.39 & 46 \\
\hline Employees & 55 & 70.51 & 20 & 25.64 & 3 & 3.85 & 78 \\
\hline Non-students & 10 & 58.82 & 7 & 41.77 & - & - & 17 \\
\hline
\end{tabular}

The above table shows that 78.79 per cent of housewives, 70.51 per cent of employees and 60.87 per cent of students respond their opinion to staff performance is high where as a good number of non-students opined that staff performance is low.

\subsection{Services of the Library}

Public library provided various services like cultural programmes, seminars, talks etc. to its potential users. Here investigator try to identify which service is most commonly used by women for their empowerment. It is shown in the table 5 .

Table 5: Services of the Library

\begin{tabular}{|l|l|l|}
\hline Services & No. of Responses & Percentage \\
\hline Reading & 76 & 43.68 \\
\hline Cultural programmes & 12 & 6.90 \\
Seminars & 6 & 3.44 \\
\hline Job oriented programmes & 80 & 45.98 \\
Total & 174 & 100 \\
\hline
\end{tabular}

The above table shows that among the various services of the library, job oriented programme comes first with 45.98 percentage. For conducting seminars the responses was only 3.44 percentage and reading with 43.68 percentage and cultural programme were 6.90 percentage. The analysis indicated that majority of the users opined that the job oriented programmes plays an important role in women empowerment.

\subsection{Internet}

Internet is the most common media for communication as well as providing information. The respondents were asked to give their opinion whether the internet facilities are beneficial for them to improve their educational, cultural and socio-political development. Hence investigator tries to identify use and purpose of using internet by women. The results are shown in the following table 6 and 7 . 
Table 6:Use of Internet

\begin{tabular}{|l|l|l|} 
Nature of response & No. of Responses & Percentage \\
\hline Positive & 31 & 17.82 \\
\hline Negative & 143 & 82.18 \\
\hline Total & 174 & 100 \\
\hline
\end{tabular}

The table 6 indicates that majority of the members of the library have negative opinion towards the use of internet. Only 17.82 percent of the members are using internet. It reveals that they are not aware about the internet services. Hence should conduct training and tutorial programmes among them to improve their use.

Table 7: Purpose of using Internet

\begin{tabular}{|l|l|l|}
\hline Purpose of using internet & No. of Responses & Percentage \\
\hline Carrier development & 15 & 48.39 \\
\hline Self Knowledge & 4 & 12.90 \\
\hline Daily purpose & 7 & 22.58 \\
\hline Entertainment & 5 & 16.13 \\
\hline Total & $\mathbf{3 1}$ & $\mathbf{1 0 0}$ \\
\hline
\end{tabular}

Table 7 depicts that a good number $(48.39 \%)$ of the women under study use internet for carrier development and 22.58 per cent of them use internet for daily purpose like gas booking, applications of various certificates, to know about fashioning of dress and related matters etc. Only 12.90 per cent of them use internet for to improve their self knowledge and 16.13 per cent of them use internet for entertainment purpose like chatting on face book, Google+, watching video etc.

\subsection{Effect of Information Technology}

Advent of Information Technology play an important role in women empowerment. Women can watch and see international level programme at anywhere. Therefore the respondents were asked to indicate their opinion about information technology whether it is helpful or not in women empowerment.

Table 8: Effect of Information Technology

\begin{tabular}{|l|l|l|}
\hline Nature of responses & No. of Responses & Percentage \\
\hline Positive & 147 & 84.48 \\
\hline Negative & 27 & 15.52 \\
\hline Total & $\mathbf{1 7 4}$ & $\mathbf{1 0 0}$ \\
\hline
\end{tabular}

The analysis shows that information technology has a positive effect on women empowerment. The majority of the respondents $(84.48 \%)$ opined that information technology have a positive effect on women empowerment.

\subsection{Use of Resources}

The resources of public library includes books, periodicals, news papers, reference materials etc. Here the investigator attempted to find out the most used resources of the library. Results are presented in table 9.

Table 9: Use of Resources

\begin{tabular}{|l|l|l|} 
Resources & No. of Responses & Percentage \\
\hline Books & 49 & 23.56 \\
Periodicals/Magazines & 54 & 31.03 \\
\hline Newspaper & 71 & 45.41 \\
\hline Internet & - & - \\
Total & $\mathbf{1 7 4}$ & $\mathbf{1 0 0}$ \\
\hline
\end{tabular}

As per the above table shows that woman respondents give first preference to newspapers $(45.41 \%)$ followed by periodicals and magazines(31.03\%) and books $(23.56 \%)$ respectively. None of the woman under study is not using internet because the library is not providing internet services.

\subsection{Resources Supporting Women Empowerment}

The respondents were asked to indicate their opinion about the supportiveness of resources for women 
empowerment. Data regarding supportiveness of resources is presented in the table 10.

Table 10: Resources Supporting Women Empowerment

\begin{tabular}{|l|l|l|} 
Resources & No. of Responses & Percentage \\
\hline Books & 39 & 22.41 \\
\hline Periodicals/Magazines & 83 & 47.70 \\
\hline $\begin{array}{l}\text { Newspaper } \\
\text { Internet }\end{array}$ & 52 & 29.89 \\
\hline Total & - & - \\
\hline
\end{tabular}

It is seen that periodicals and magazines $(47.70 \%)$ are the most supportive resources among women followed by Newspapers $(29.89 \%)$ and books $(22.41 \%)$. No women under the study opined that internet is not supporting them. A good number of the woman users think periodicals and magazines are supporting women empowerment the most.

\subsection{Women Empowerment Programmes}

Public library offered various programmes to its users in social, cultural and technological field. Hence the investigator tried to find out among these programmes, which programmes is most helpful for women empowerment and the collected information is analysed in the table 11.

Table 11: Women Empowerment Programmes

\begin{tabular}{|l|l|l|} 
Programmes & $\begin{array}{l}\text { No. of responses } \\
\text { Social }\end{array}$ & $\begin{array}{l}\text { Percentage } \\
46\end{array}$ \\
\hline Financial & & - \\
\hline Cultural & 50 & 28.73 \\
Technological & 48 & 27.59 \\
\hline Total & $\mathbf{1 7 4}$ & $\mathbf{1 0 0}$ \\
\hline
\end{tabular}

The social programmes organised by the library is most effective in women empowerment (43.68 per cent) followed by technological programmes ( 27.59 per cent). The analysis shows that the library programmes are not supporting women in improving their financial status.

\section{Major Findings Of The Study}

1. Majority of the users opined that the job oriented programmes plays an important role in women empowerment.

2. The library does not provide internet facilities to the users and majority of the users are not aware of the information technology applications.

3. A good number of the women under study use internet for carrier development.

4. The majority of the respondents opined that information technology have a positive effect on women empowerment.

5. Woman respondents give first preference to newspapers $(45.41 \%)$ followed by periodicals and magazines $(31.03 \%)$ and books $(23.56 \%)$ respectively

6. Periodicals and magazines are the most supportive resources among women followed by Newspapers

7. Majority of the users think social programmes organised by the library supports women empowerment.

\section{Suggestions For Improvement}

The following suggestions were put forward by the investigator

1. Provide better Internet services in the library thereafter it can act as parallel organisation for formal and nonformal purpose of its users.

2. Conduct orientation programmes and training programme for women users in information technology may help them to make better utilisation of resources available in Internet.

3. A greater interaction between library staff and users is needed for the maximum utilization of the resources.

4. Conduct exhibitions, talks on special topic like woman empowerment, motivation, psychological aspects, globalisations etc.

5. Conduct carrier guidance classes on various courses, examinations, programmes and projects offered by state and central Governments.

6. Increase the opening hours of the library for facilitating more users. 


\section{Conclusion}

Public library is very important in the life of any nation. It attempts to meet various needs of readers, provide various information sources and services. Public library play important role in women empowerment process. Hence it has been established as a crucial place in the life of women, as it provides information that is essential for the women empowerment. It will help for their own development, family and community development. From the analysis, it stated that library has to play a vital role for the improvement of women. Various information sources of the library are not sufficient to meet the needs of women users and the infrastructure and facilities of the library has to be improved. Majority of the women under study are not aware of the information technology applications. Hence there is an urgent need for effective orientation programmes, workshops, seminars etc among women that only they can exploit the maximum benefit from application of information technology.

\section{References}

[1]. Ravikumar, S. K. (2006). Indian women. ( $1^{\text {st }}$ ed., pp.32-46). Jaipur: Mangal deep publications

[2]. Bhuvaneshwari Ravi, \& Gayathri Vivek, (2014). Importance of partnership for development of public libraries in India. DESIDOC Journal of Library and Information Technology, 33(1), 12-20.

[3]. Kaliya, Perumal, \& Baskaran,S,. (2010). Infoarmation seeking behaviour of rural folk in Tamil nadu : A case study of Peramakudi branch libray. Kelpro Bulletin, 4(2), 49-59.

[4]. UNESCO Manifesto. (2014). Retrieved January 17, 2014 from http://unesco.org.

[5]. Laila T Abraham. (2014). Role of public libraries in non-formal education in Kerala. Kelpro Bulletin, 14(2), 60-67.

[6]. Ibid.3

[7]. Abdul Kalam, A P J, \& Sivathanu Pillai. (2004). Envisioning an empowered nation (1 ${ }^{\text {st }}$ ed.,pp.19-21). New Delhi: Tata Mc Graw hill publishing company Limited.

[8]. Usha Sharma. (2003). Women in South Asia Employment Empowerment and Human Development(1 ${ }^{\text {st }}$ ed,pp.1-25). Delhi: Authors press.

[9]. Suguna B., \& Sandhya Rani, (2008). Health status of women welfare and empowerment in India (1st ed., pp.110-123). New Delhi: New century publication.

[10]. K V Singh, (2007). Women issues empowerment and gender discrimination (1st ed., pp.51-52). Delhi: Vista international publishing house.

[11]. Gutam, J. N., \& Sunil kumar. (2004). Community Information and Library service for rural people, information communication library and community development (1st ed., pp.410-412) Delhi: B R publishing corporation. 